University of Nebraska - Lincoln

DigitalCommons@University of Nebraska - Lincoln

\title{
Blast-induced Mild Traumatic Brain Injury through Ear Canal: A Finite Element Study
}

\author{
Praveen Akula \\ University of Nebraska-Lincoln, praveenakula20@gmail.com \\ Yi Hua \\ University of Nebraska-Lincoln, yhua3@unl.edu \\ Linxia Gu \\ University of Nebraska-Lincoln, gul@fit.edu
}

Follow this and additional works at: https://digitalcommons.unl.edu/mechengfacpub

Part of the Biomechanics and Biotransport Commons, Dynamics and Dynamical Systems Commons, Other Biomedical Engineering and Bioengineering Commons, and the Other Medicine and Health

Sciences Commons

Akula, Praveen; Hua, Yi; and Gu, Linxia, "Blast-induced Mild Traumatic Brain Injury through Ear Canal: A Finite Element Study" (2015). Mechanical \& Materials Engineering Faculty Publications. 129.

https://digitalcommons.unl.edu/mechengfacpub/129

This Article is brought to you for free and open access by the Mechanical \& Materials Engineering, Department of at DigitalCommons@University of Nebraska - Lincoln. It has been accepted for inclusion in Mechanical \& Materials Engineering Faculty Publications by an authorized administrator of DigitalCommons@University of Nebraska Lincoln. 


\title{
Blast-induced Mild Traumatic Brain Injury through Ear Canal: A Finite Element Study
}

\author{
Praveen Akula, Yi Hua, and Linxia Gu \\ Department of Mechanical and Materials Engineering, University of Nebraska-Lincoln, Lincoln, NE 68588-0656
}

Corresponding author — Linxia Gu, Nebraska Center for Materials and Nanoscience, Lincoln, NE 68588-0656;

tel 402-472-7680, fax 402-472-1465, email lgu2@unl.edu

\begin{abstract}
Purpose The role of ear canal in transmitting blast waves to the brain is not clear. The goal of this work is to characterize the influence of ear canal on blast-induced mild traumatic brain injury through a computational approach.

Methods A three-dimensional human head model with single-side ear canal details was reconstructed from computed tomography images. The ear canal was positioned either facing the incident blast wave or facing away from the blast wave.

Results The blast wave-head interaction has demonstrated that the overpressure within the ear canal was substantially amplified when the ear directly faced the blast wave. When it faced away from the blast wave, the overpressure within the ear canal was less than the actual incident blast pressure. Regardless of the substantial pressure differences within the ear canal induced by the blast wave, the resulting intracranial pressures were almost the same for both cases.

Conclusions The blast wave-head interaction has demonstrated that the role of the ear canal in brain dynamics, and thus brain injury, was negligible. However, the peak overpressure within the ear canal exceeded the documented tympanic membrane rupture and inner ear damage thresholds. This was speculated to cause the degeneration of axons along the auditory pathway up to the midbrain. This work provided fundamental understanding of the load transmission through the ear canal and could serve as a platform for designing better protective armors.
\end{abstract}

Keywords: Ear canal, Blast, Traumatic brain injury, Finite element modeling, Stress transfer

\section{Introduction}

Blast-induced neurotrauma is one of the principal causes of casualties in the Iraq and Afghanistan wars [1]. Although improved head protective equipment has provided better protection from injuries resulting from blunt impacts, shrapnel or projectiles, they are not designed for protection against blast waves, leading to an increased incidence of mild traumatic brain injury (mTBI) [2]. The mTBI is often sustained without any signs of external injury or any visible findings from magnetic resonance imaging, making it difficult to identify the exact cause and potential injury mechanisms. Several potential injury mechanisms are proposed, including direct transmission of pressure waves through the cranium, skull flexure, and propagation of pressure pulse through the thorax [3-5]. Recently, high incidence of ear injuries during blast events also led to a hypothesis that blast waves could surge into the brain through the ear canal or opening $[6,7]$. Shock tube tests on a spherical gelatin filled skull-brain surrogate have shown an increased intracranial pressure (ICP) and impulse due to the presence of openings in the skull $[8,9]$. In addition, the role of openings in the ICP is also found to be dependent on brain materials. An eggshaped head surrogate test showed no remarkable changes in positive intracranial pressure, but the tensile stress at the posterior location of the head was decreased by $21 \%$ for the surrogate with openings [10]. Although these studies have demonstrated the influence of openings on the brain dynamics, the limitation is that an opening is generally considered as a through-hole which exposes the brain directly to the air. This contradicts the fact that the human brain is a closed entity and the ear opening is a blind hole with a certain depth. In addition, the diameters of openings in 
previous studies $[8,9]$ are clinically irrelevant and do not fall within the anatomical range of the ear canal $(5 \sim 10$ $\mathrm{mm}$ in diameter). These limitations might overestimate the role of the ear canal in the blast-induced mTBI.

The goal of this work is to ascertain whether the ear opening has any prominence in altering the brain responses under blast loading conditions. A three-dimensional (3D) human head model with single-side ear canal details was reconstructed from computed tomography (CT) data. It was then subjected to blast loadings using numerical analysis. Two cases, i.e., ear opening facing away from the blast (case 1) and ear opening facing the blast (case 2), were investigated. The intensity of blast overpressures that exerted at the vicinity of the head and within the ear opening was monitored. The brain responses in terms of ICP were also computed.

\section{Materials and Methods}

A human head model (Figure 1) was reconstructed from CT data, which consisted of 73 axial scans of 5122 pixels taken at $3 \mathrm{~mm}$ intervals in a male head. The image data were segmented into three different tissue types of the head, i.e., skull, cerebrospinal fluid (CSF), and brain. The segmentation was realized using the 3D image analysis algorithm implemented in Mimics ${ }^{\circledR}$ (Materialise, Inc., Leuven, Belgium). The skull included most of the anatomical structures such as the zygomatic bone, mandible, and eye sockets. Since it is very time-consuming to capture the miniature configuration of the ear canal, only the right ca- nal (approximately $8 \mathrm{~mm}$ in diameter and $32 \mathrm{~mm}$ in depth) was reconstructed. Followed by segmentation, the head model was imported into HyperMesh ${ }^{\circledR}$ (Altair Engineering, Inc., MI, USA) through an STL file and discretized into 159,621 10-noded modified quadratic tetrahedron elements (C3D10M). The adopted element size of $2 \mathrm{~mm}$ was based on a mesh convergence study [11]. The head model was then subjected to a planar blast loading mimicking our in-house shock tube as described in our previous work [5]. Briefly, the measured incident pressure history with peak value of $0.22 \mathrm{MPa}$ was used as the pressure boundary condition at the inlet of the Eulerian domain $(400 \times$ $400 \times 1000 \mathrm{~mm}$ ) filled with air. It consisted of 1,171,566 brick elements with appropriate mesh refinement near the region of the human head to capture the effect of fluidstructure interaction. The velocity, i.e., the time derivative of displacement, perpendicular to each face of the Eulerian domain was kept equal to zero to avoid escaping/leaking of air through these faces [12]. This would create a planar blast front traveling along the incident direction without lateral flow. The head model was immersed in the Eulerian domain and their interaction was enforced through a penalty contact algorithm with frictionless tangential sliding and hard contact normal behavior. The blast-head interaction model, governed by partial differential equations of conservation of mass, momentum and energy along with the material constitutive equations and boundary conditions, was solved in ABAQUS/explicit analysis software (Simulia, Inc.) [13].

The skull was modeled as a homogeneous linear elas-

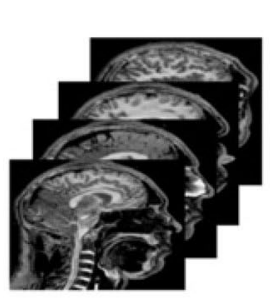

CT images

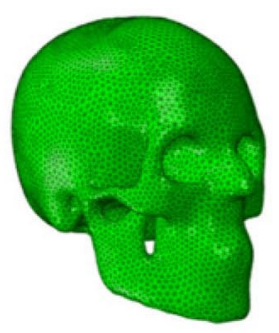

Human head assembly
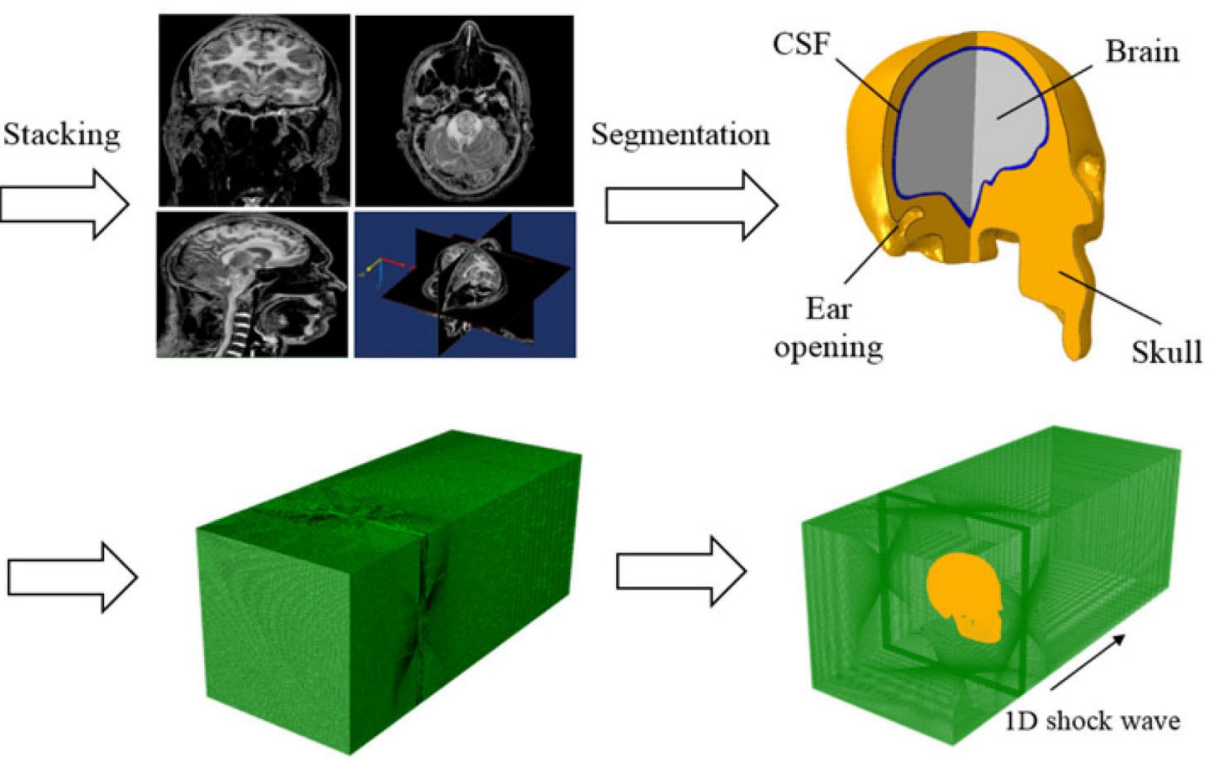

Shock tube modeled with Eulerian elements

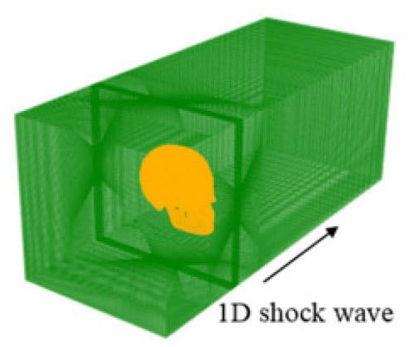

Lagrangian body immersed in Eulerian elements

Figure 1. Finite element modeling. 
Table 1. Material properties.

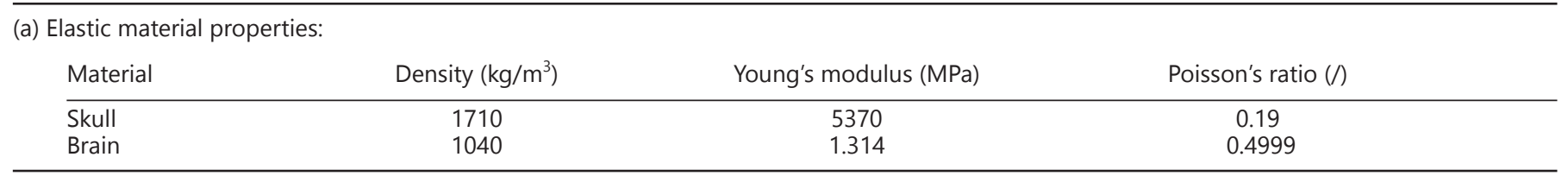

(b) Viscoelastic material properties:

\begin{tabular}{lcccc} 
Material & Short-term shear modulus $(\mathrm{kPa})$ & Long-term shear modulus $(\mathrm{kPa})$ & Decay constant $(\mathrm{ms})$ \\
\hline Brain & 41 & 7.8 & 700 \\
\hline
\end{tabular}

(c) Incompressible fluid EOS parameters:

\begin{tabular}{lcccc} 
Material & Viscosity $(\mathrm{Ns} / \mathrm{mm} 2)$ & Sound speed $(\mathrm{mm} / \mathrm{s})$ & Hugoniot slope coefficient $(/)$ & Grüneisen's gamma $(/)$ \\
\hline $\mathrm{CSF}$ & $1 \times 10^{-8}$ & $1.48 \times 10^{6}$ & 0 & 0 \\
\hline
\end{tabular}

(d) Ideal gas EOS parameters:

\begin{tabular}{lccc} 
Material & Density $(\mathrm{kg} / \mathrm{m} 3)$ & Gas constant $(\mathrm{J} / \mathrm{kgK})$ & Temperature $(\mathrm{K})$ \\
\hline Air & 1.1607 & 287.05 & 300
\end{tabular}

tic isotropic material and the Young's modulus and Poisson's ratio were assumed as $5.37 \mathrm{GPa}$ and 0.19 , respectively [14]. The brain was assumed to be linear viscoelastic with a shortterm shear modulus of $41 \mathrm{kPa}$ and a long-term shear modulus of $7.8 \mathrm{kPa}$ [15]. The CSF was modeled as an incompressible fluid using the linear Mie-Grüneisen equation of state (EOS), which related the blast velocity and fluid particle velocity to the pressure inside the CSF [16]. Air was modeled using an ideal gas EOS since the Mach number of the blast front measured in our previous experiment was approximately 1.4 , and the ratio of specific heats did not change drastically at this Mach number [17]. A summarization of the material properties is illustrated in Table 1.

\section{Model Verification}

The anatomically detailed 3D finite element (FE) head model with the ear canal was verified against the frontal cadaveric impact experiment conducted by Nahum et al. [18]. In Nahum's experiment, the seated stationary cadaver subject was impacted at the frontal bone of the skull by a rigid mass traveling at a constant velocity. The intracranial pressures were measured at four different locations, in which location N1 was in the frontal bone adjacent to the impact site, location N2 was immediately posterior and superior to the coronal and squamosal sutures in the parietal bone, location N3 was inferior to the lambdoidal suture in the occipital bone, and location N4 was in the occipital bone at the posterior fossa.

To replicate Nahum's experiment, the measured impact force from the cadaver test was applied to the frontal bone of the skull in the anterior-posterior direction, in the form of a distributed load over an area of 1,300 mm2 (Figure 2a). Intracranial pressure histories were extracted at four different locations (Figure $2 b$ ) corresponding to those measured in Nahum's experiment and the comparison results were shown in Figure $2 \mathrm{c}$. It is observed that the intracranial pressures predicted by the FE model agreed well with the experiment at locations N2 and N3; however, at locations $\mathrm{N} 1$ and N4, the pressures predicted by the FE model were much larger. This could be attributed to several factors such as the discrepancies in head geometry, material properties and boundary conditions, lacking intricate details of meningeal layer and exact locations of pressure sensors; all of these could cumulatively contribute to the differences. The intracranial pressure pattern predicted by the FE model was depicted in Figure $2 \mathrm{~d}$. A typical coup and contrecoup pattern was observed, and the pressure varied continuously along the mid-sagittal plane. This is consistent with the pressure pattern as reported by other researchers under frontal impact loading conditions $[14,19]$.

\section{Results}

The role of the ear canal in transmitting the blast load into the brain was studied through two cases as shown in Figure 3. When the head model was positioned such that the ear opening faced away from the blast (case 1), the opening was unlikely to affect the intracranial responses. This is due to the fact that the peak intracranial pressures/ stresses have already been established in the brain well before the opening directly interacted with the blast front. On the contrary, case 2 positioned the head to expose the ear opening directly facing the oncoming blast. Then the 
a

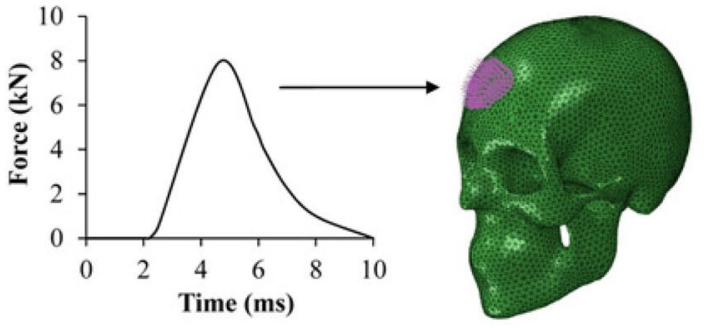

b

Location N1

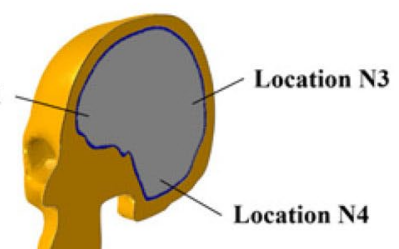

Location N2 not shown in the figure is located superior to squamosal suture.
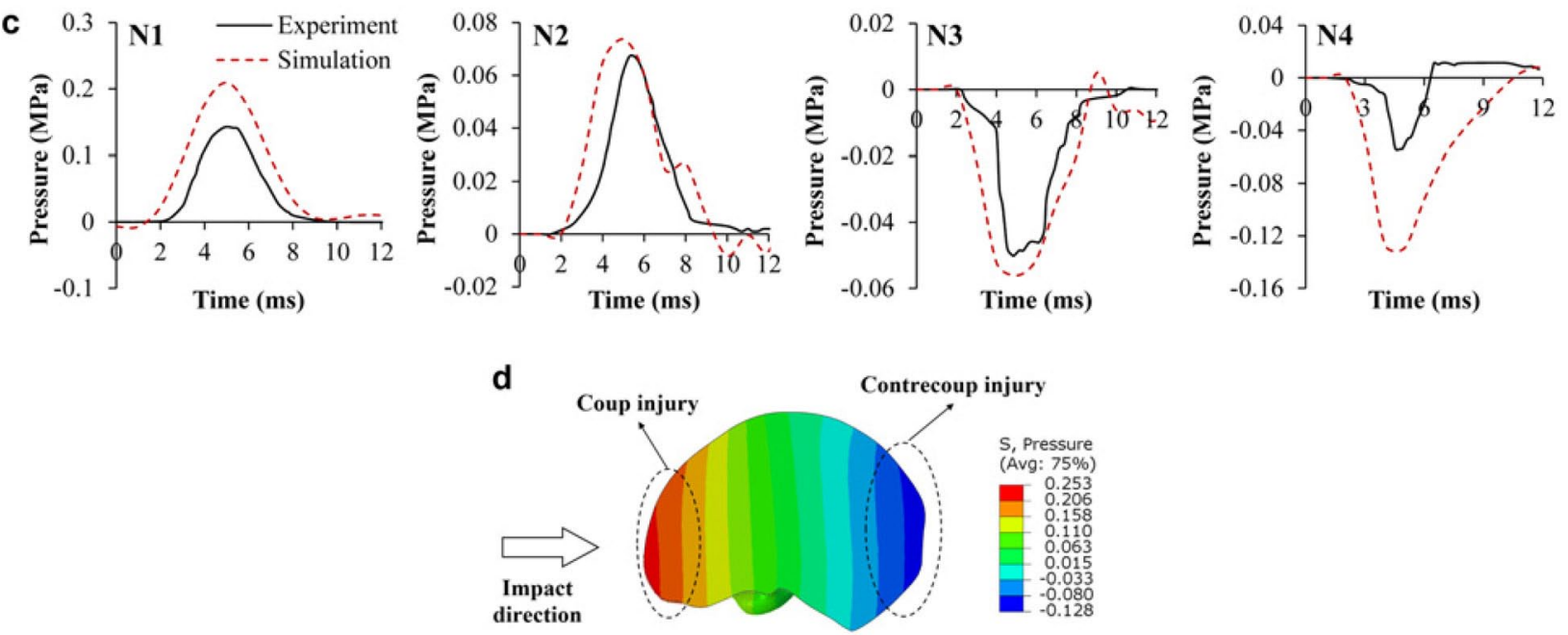

Figure 2. Verification of CT-based head model with Nahum's experiment. (a) Head model subjected to Nahum's experiment; (b) Locations at which pressure comparisons were made; (c) Comparison results of pressure histories; (d) Pressure pattern in the brain at $\mathrm{t}=5 \mathrm{~ms}$.

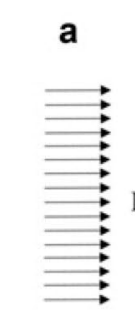

Shock wave incidence

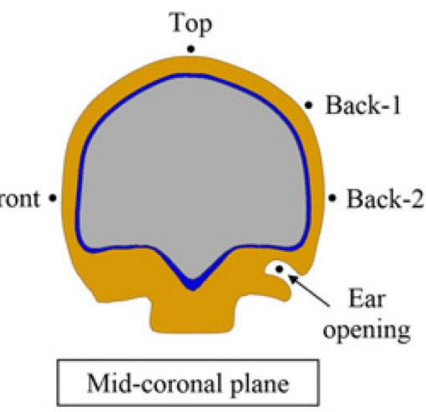

b

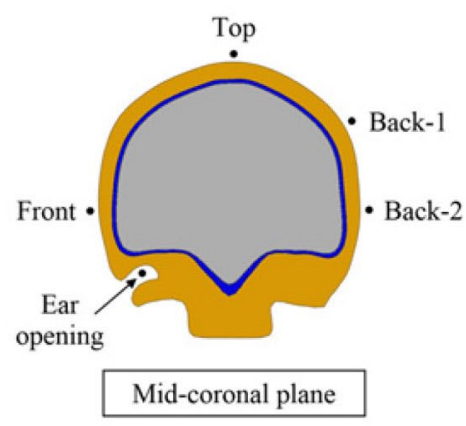

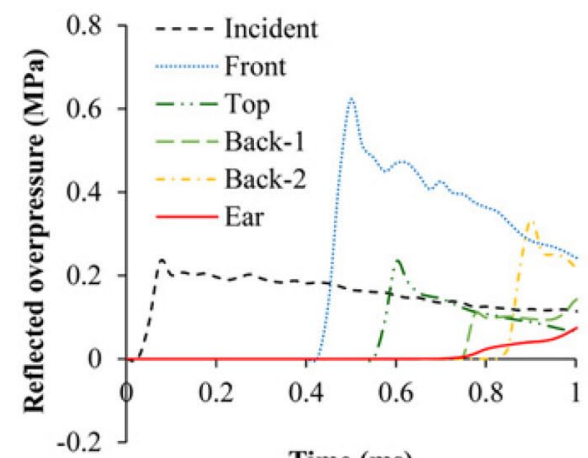

Time (ms)

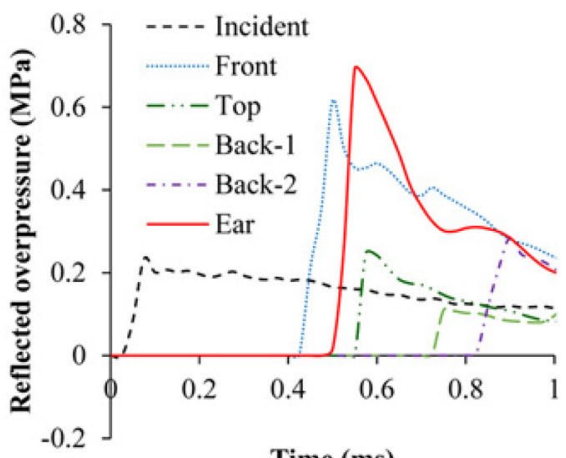

Time (ms)

Figure 3. Reflected overpressures around the head: (a) Ear opening facing away from the blast, and (b) Ear opening facing the blast. 
opening affected the intracranial responses. Therefore, any differences in the peak brain responses between the two cases were attributed to the ear opening, given that all the other parameters, including blast load, Eulerian mesh, and boundary condition remained constant.

\section{Blast - head interactions}

The blast loading on the head can be estimated by monitoring the reflected overpressures around the head at various locations (Figure 3). In case 1, the highest reflected overpressure of $0.62 \mathrm{MPa}$ was observed at the front location. Compared to the incident pressure, the reflection factor $\Lambda$, i.e., the ratio of reflected overpressure to incident pressure, was calculated as 2.8. However, the overpressure within the ear opening was found to be minimal and only with a peak value of $0.10 \mathrm{MPa}(\Lambda=0.45)$. In case 2 , the highest reflected overpressure of $0.70 \mathrm{MPa}(\Lambda=3.2)$ was observed within the ear opening, and the observations at other locations were the same as the case 1 . The peak overpressure inside the ear canal in case 2 was approximately 7 times greater than that in case 1 . It is also observed that the peak overpressure measured at back location 2 was $0.33 \mathrm{MPa}(\Lambda=1.3)$, which was higher than that of $0.22 \mathrm{MPa}(\Lambda=1.0)$ at the top and $0.15 \mathrm{MPa}(\Lambda=$ $0.68)$ at back location 1.

\section{Intracranial pressure}

The propagation of pressure waves in the coronal plane of the brain is illustrated in Figure 4. There was negligible difference between the two cases, therefore we only showed the results from case 1 . The peak positive ICP (compression) is observed at the frontal location at 0.5 ms with a smooth pressure front. The pressure wave propagated and reached the posterior end at $0.55 \mathrm{~ms}$ when the reflection/refraction took place at the brain/skull interfaces and gave rise to complex pressure distribution in the brain. At approximately $0.65 \mathrm{~ms}$, the peak negative ICP (tension) of $-0.27 \mathrm{MPa}$ is observed at the posterior location. The pressure distribution in the brain portrayed a classical coup and countercoup pattern.

The detailed ICP histories at four distinct locations in the mid-coronal plane of the brain are depicted in Figure
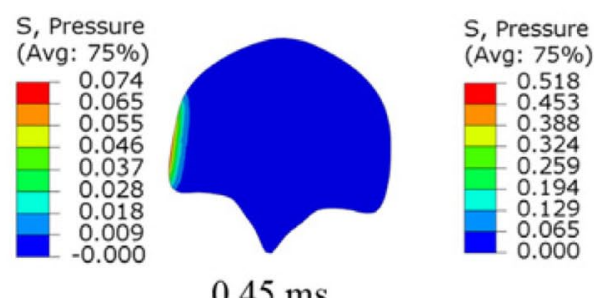

$0.45 \mathrm{~ms}$
5. Location $\mathrm{P} 1$ is the site close to the ear opening, where one can expect the effect of the ear opening on intracranial tissue responses, if any exists. Location P2 is the site with close proximity to the blast source (coup site). Location P3 is approximately at the center of the brain, and location P4 is exactly opposite to the site of blast impact (countercoup site), which is considered to be the most vulnerable region for the cavitation type of brain injury. It is clear that there was no significant difference in ICP histories between the two cases, although the head model in case 2 predicted much larger reflected overpressure within the ear canal. As the blast front propagated and reached specific locations, the first peak ICP in both cases was observed as $0.47 \mathrm{MPa}$ at location $\mathrm{P} 2$, followed by $0.38 \mathrm{MPa}$ at location P1, $0.24 \mathrm{MPa}$ at location $\mathrm{P} 3$, and $0.11 \mathrm{MPa}$ at location P4, respectively. The blast front-induced ICP attenuated by approximately $76.6 \%$ as the wave propagated from the coup site P2 to the countercoup site P4. In addition, these ICPs were also the maximum values except the posterior location $\mathrm{P} 4$, which rose to $0.25 \mathrm{MPa}$ at a later time $\mathrm{t}=0.95 \mathrm{~ms}$. The ICP histories in the mid-sagittal plane of the brain were also measured and again, there was no appreciable difference between the two cases (results not shown for brevity).

\section{Discussion}

It is well known that ears are the most vulnerable organs under blast loading conditions. Recently it was also speculated that the ear canal might affect how the blast wave surged into the brain $[6,7]$. However, no study has been performed to date that has concretely focused on investigating the effect of ear openings on intracranial tissue. In this work, a 3D human head model with single-side ear canal details was reconstructed to examine the role of the ear canal in transmitting the blast wave into brain dynamics. The model was first verified against the cadaveric impact experiment conducted by Nahum et al. [18] and reasonable agreement has been achieved (Figure 2c). In addition, the modeling framework was also validated by our in-house experiments $[5,12]$. The verified model was then placed inside the shock tube (Eulerian domain) and
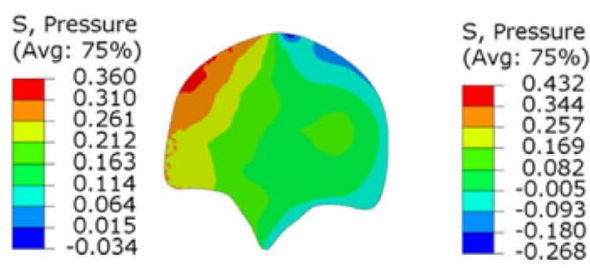

$0.55 \mathrm{~ms}$

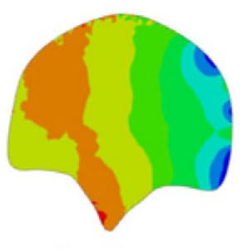

$0.65 \mathrm{~ms}$

Figure 4. Illustration of the intracranial pressure wave propagation in the coronal plane of the brain. 

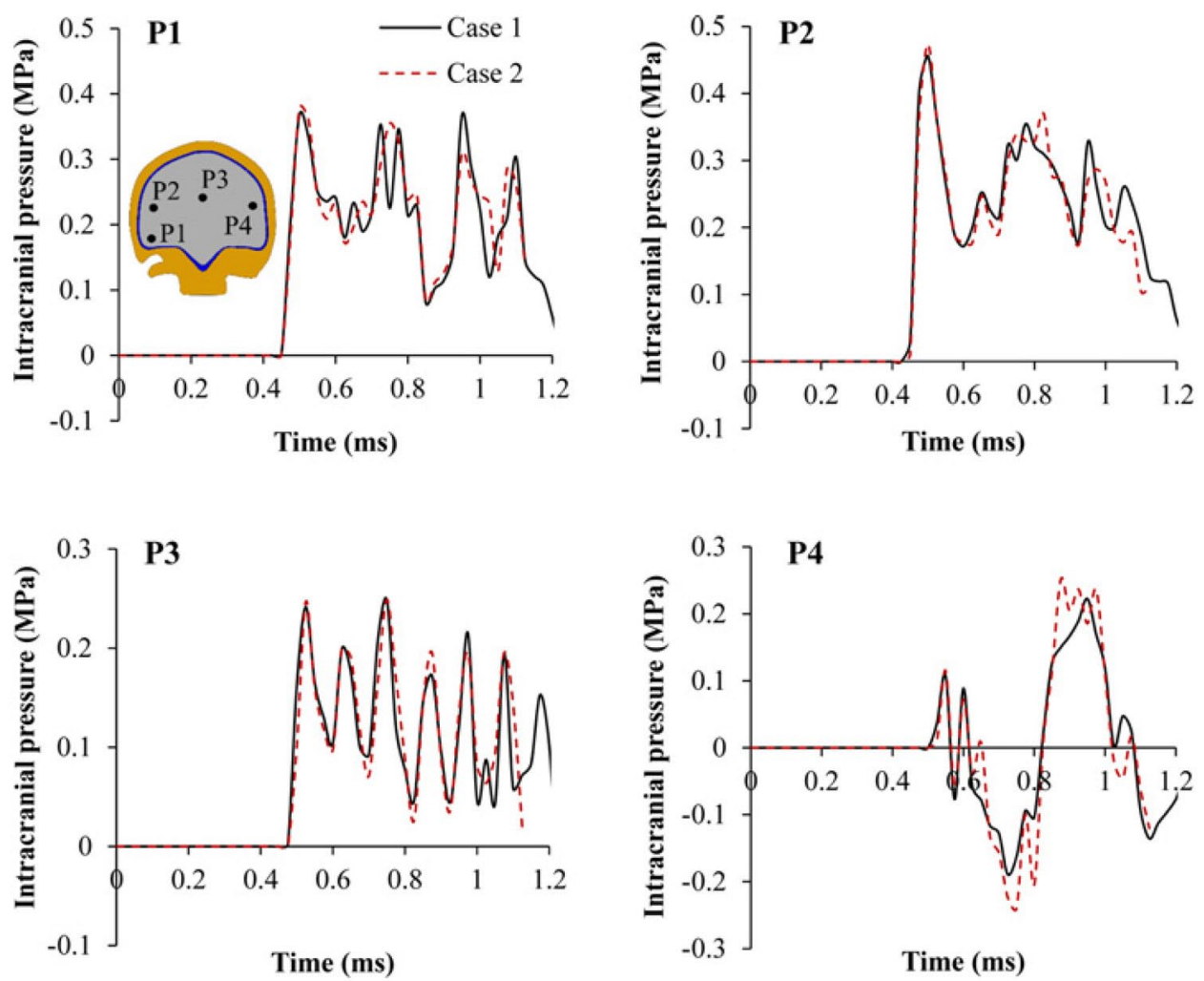

Figure 5. Comparison of the intracranial pressure histories at four different locations (P1 - P4) in the mid-coronal plane of the brain.

subjected to the experimental measured blast loading. To characterize the role of the ear canal in blast-induced mTBI, two different cases were simulated. In the first case, the ear opening was facing away from the blast, and in the second case, the ear opening was facing the blast.

The maximum reflected pressure was observed within the ear canal when it was facing the incident blast wave, and the minimum reflected pressure was observed when it was facing away from the incident wave. The flow dynamics across the head were used to explain the pressure variation inside the ear canal (Figure 6). When the ear opening faces the incident wave, the blast overpressure can easily gush into the ear canal without obstruction, thereby acting like a funnel focusing the blast wave a

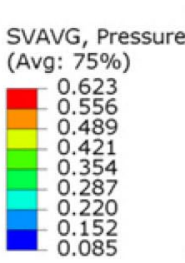

b

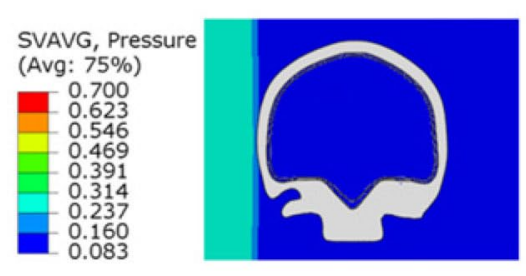

$\mathrm{t}=\mathbf{0 . 4 5} \mathrm{ms}$

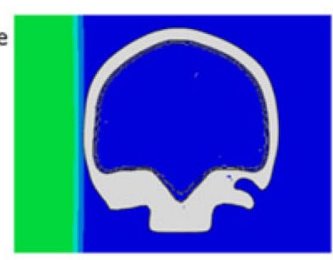

$\mathrm{t}=\mathbf{0 . 4 5} \mathrm{ms}$

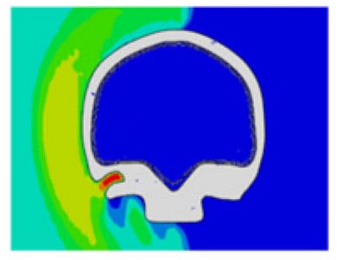

$\mathrm{t}=\mathbf{0 . 6 0} \mathrm{ms}$

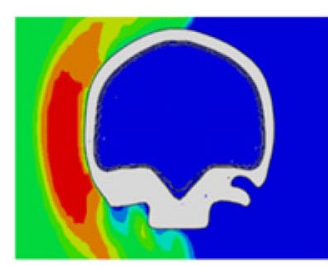

$\mathrm{t}=0.60 \mathrm{~ms}$$$
\mathrm{t}=\mathbf{0 . 6 0 \mathrm { m }}
$$

Flow

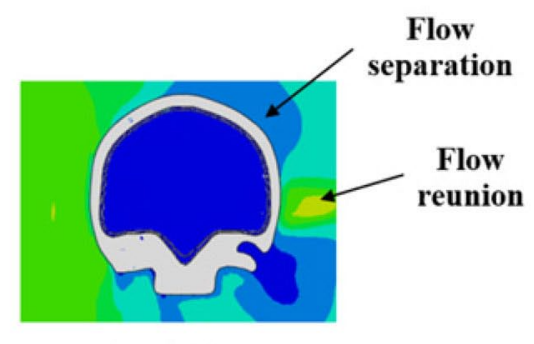

$\mathrm{t}=0.90 \mathrm{~ms}$

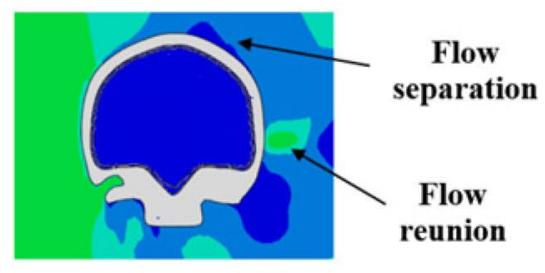

$\mathrm{t}=0.90 \mathrm{~ms}$

Figure 6. Snapshots of the blast wave propagation and its interaction with the head: (a) Ear opening facing away from the blast, and (b) Ear opening facing the blast. 
at a small area. This results in significant pressure amplification within the ear canal. In the case of the ear opening facing away from the blast wave, hardly any blast wave can enter into the ear canal and the reflected overpressure within the ear canal was even lower ( 50\%) than the actual incident pressure.

The flow dynamics across the head indicate that there is a significant amount of loading that only takes place at the frontal and posterior locations. At the frontal location of the head, the pressure amplification is caused by sudden obstruction of the blast flow. As the blast wave continues to flow across the head, due to the high velocity of the blast wave and geometry of the head, the flow separates at the top and side locations, which again reunites at the posterior location. This led to an increase in blast overpressure at the posterior location of the head. This flow separation and reunion are likely to occur with any kind of head models; however, the location of flow separation and union depends on the geometry of the exploded subject, as well as the intensity and velocity of the blast. Thus the flow obstruction, separation, and reunion cause differential loading across the head. Also, there is a significant amount of loading within the ear canal that only occurs when the ear opening is facing the blast (case 2).

Although there was a significant amount of loading within the ear canal in case 2, the ICP responses were almost the same with case 1 (Figure 5). This indicated that the role of the ear canal in intracranial tissue responses was negligible. One possible reason is that the aggravated reflected overpressure within the ear canal is acting over a relatively small area compared to the head surface, making its contribution to brain dynamic minimal. However, various studies in which animals are subjected to blasts or extreme acoustic loadings have shown that the damage to the inner ear can induce cellular level injuries to the brain $[7,9]$. For example, a chinchilla study showed that hair cell loss was well correlated with the axonal degeneration or damage in the central nervous system [20].

Efforts have then been made to identify the injury thresholds of the ear. Much testing data are available for predicting the tympanic membrane (TM) rupture, since it is the most common otologic injury subjected to blast. Several experiments have been performed on animals and cadavers to determine the TM rupture threshold, but with significant variations [21-24]. These variations might depend on the blast load properties; the physical features of the external ear such as the geometry of the ear canal (length, diameter, and shape); the histological features of the membrane itself; and the history of previous exposure to the noise $[25,26]$. Regardless of the variations,
$0.1 \mathrm{MPa}$ has been considered as the threshold value for $50 \%$ of incidents of human TM rupture under blast loading conditions [24,25]. The lower limit of this threshold is estimated as $0.03 \mathrm{MPa}$. It should also be noted that inner ear organs are more susceptible to damage than middle ear organs [27].

The documented injury threshold of ears was compared with our predicted peak overpressures within the ear canal, i.e., $0.10 \mathrm{MPa}$ in case 1 and $0.70 \mathrm{MPa}$ in case 2 . Both cases indicated a fair chance of cellular level injury to the brain emerging through ear damages. The extent and severity of the cellular level of brain injuries in case 2 was expected to be larger than case 1 due to the relatively higher blast loadings. It should be pointed out that the reflected blast overpressure within the ear canal might be overestimated without considering the detailed configuration of the ear. Details such as the pinna, auricles, and concha were expected to be added into future versions of our models.

\section{Conclusions}

This work has demonstrated that the ear canal is not the primary transduction pathway of blast energy to the brain. The conclusions are summarized as following:

- Blast overpressure can be substantially amplified within the ear canal when it directly faces the blast wave. When the ear faces away from the blast wave, the blast overpressure within the ear canal is less than the actual incident pressure.

- The reflected pressure within the ear canal, even facing the blast wave, has minimal impact on the brain dynamics, however it induced damage to the ear organ, which might cause brain injury through the auditory pathway to the brain.

Findings from this work can contribute to a deeper understanding of the role of the ear canal during a blast event, and help develop better protective measures against blast-induced mTBI.

Acknowledgments - The authors gratefully acknowledge the financial support provided by the Edgerton Innovation Award at the University of Nebraska-Lincoln College of Engineering, and the U.S. Army Research Office project "Army-UNL Center for Trauma Mechanics" (Contract No. W911NF-08-10483). The authors have no conflict of interest in relation to the work in this article. 


\section{References}

[1] Warden D. Military TBI during the Iraq and Afghanistan wars. J Head Trauma Rehabit. 2006; 21(5):398-402.

[2] Kleinschmit NN. A shock tube technique for blast wave simulation and studies for flow structure interactions in shock tube blast experiments. Masters thesis; University of Nebraska- Lincoln; USA; 2011.

[3] Moss WC, King MJ, Blackman EG. Skull flexure from blast waves: a mechanism for brain injury with implications for helmet design. Phys Rev Lett. 2009; doi:10.1103/PhysRevLett. 103.108702.

[4] Courtney AC, Courtney MW. A thoracic mechanism of mild traumatic brain injury due to blast pressure waves. Med Hypotheses. 2009; 72(1):76-83.

[5] Hua Y, Akula PK, Gu L, Berg J, Nelson CA. Experimental and numerical investigation of the mechanism of blast wave transmission through a surrogate head. J Comput Nonlin Dyn. 2014; doi:10.1115/1.4026156.

[6] Mao JC, Pace E, Pierozynski P, Kou Z, Shen Y, VandeVord P, Haacke EM, Zhang $X$, Zhang J. Blast-induced tinnitus and hearing loss in rats: behavioral and imaging assays. J Neurotrauma. 2012; 29(2):430-44.

[7] Arun P, Valiyaveettil M, Biggemann L, Alamneh Y, Wei Y, Oguntayo S, Wang Y, Long JB, Nambiar MP. Modulation of hearing related proteins in the brain and inner ear following repeated blast exposures. Interv Med Appl Sci. 2012; doi:10.1556/ IMAS.4.2012.3.2.

[8] Varas JM, Philippens M, Meijer S, Van Den Berg A, Sibma P, Van Bree J, De Vries D. Physics of IED blast shock tube simulations for mTBI research. Front Neurol. 2011; doi:10.3389/ fneur.2011.00058.

[9] Alley MD, Schimizze BR, Son SF. Experimental modeling of explosive blast-related traumatic brain injuries. Neuroimage. 2011; doi:10.1016/j.neuroimage.2010.05.03.

[10] Zhu F, Wagner C, Dal Cengio Leonardi A, Jin X, VandeVord $\mathrm{P}$, Chou $\mathrm{C}$, Yang $\mathrm{KH}$, King Al. Using a gel/plastic surrogate to study the biomechanical response of the head under air shock loading: a combined experimental and numerical investigation. Biomech Model Mechanobiol. 2012; doi:10.1007/ s10237-011- 0314-2.

[11] Akula P. Blast induced traumatic brain injury: role of ear openings. Masters thesis; University of Nebraska-Lincoln; USA; 2013.

[12] Ganpule S, Gu L, Alai A, Chandra N. Role of helmet in the mechanics of shock wave propagation under blast loading conditions. Comput Methods Biomech Biomed Engin. 2012; doi:10.1080/10255842.2011.597353.
[13] Abaqus benchmark manual. Providence; Rhode Island; USA; 2008.

[14] Zhang L, Yang KH, Kin, Al. Comparison of brain responses between frontal and lateral impacts by finite element modeling. J Neurotrauma. 2001; 18(1):21-30.

[15] Sundaramurthy A, Alai A, Ganpule S, Holmberg A, Plougonven $E$, Chandra N. Blast-induced biomechanical loading of the rat: an experimental and anatomically accurate computational blast injury model. J Neurotrauma. 2012; doi:10.1089/ neu.2012.2413.

[16] Chafi MS, Dirisala V, Karami G, Ziejewski M. A finite element method parametric study of the dynamic response of the human brain with different cerebrospinal fluid constitutive properties. Proc Inst Mech Eng H. 2009; 223(8):1003-19.

[17] Hua Y, Akula P, Gu L. Experimental and numerical investigation of carbon fiber sandwich panels subjected to blast loading. Compos Part B Eng. 2014; 56(1):456-63.

[18] Nahum AM. Intracranial pressure dynamics during head impact. Conf Proc Stapp Car Crash. 1977; doi:10.4271/770922.

[19] Chen Y, Ostoja-Starzewski M. MRI-based finite element modeling of head trauma: spherically focusing shear waves. Acta Mech. 2010; 213(1):155-67.

[20] Morest DK, Bohne BA. Noise-induced degeneration in the brain and representation of inner and outer hair cells. Hear Res. 1983; 9(2):145-51.

[21] Zalewski T. Experimentelle Untersuchungen uber die Resistenzfahigkeit des Trommelfells. Z Ohrenheilkd. 1906; 52(1):109.

[22] James DJ, Pickett VC, Burdette KJ, Cheesman A. The response of the human ear to blast, part 1: the effect on the ear drum of a short duration, fast rising pressure wave. AWRE/CDE Report No. 04/82; 1982.

[23] Keller AP. A study of the relationship of air pressure to myringorupture. Laryngoscope. 1958; 68(12):2015-29.

[24] Hirsch FG. Effects of overpressure on the ear: a review. Ann N Y Acad Sci. 1968; 152(1):147-62.

[25] Richmond DR, Yelverton JT, Fletcher ER, Phillips YY. Physical correlates of eardrum rupture. Ann Otol Rhinol Laryngol Suppl. 1989; 140(1):35-41.

[26] White CS, Bowen IG, Richmond DR. The relation between eardrum failure and blast-induced pressure variations. Space Life Sci. 1970; 2(2):158-205.

[27] Kringlebotn M. Rupture pressures of membranes in the ear. Ann Otol Rhinol Laryngol. 2000; 109(10):940-4. 